\title{
Elucidating Mechanisms behind Ambient Storage-Induced Efficiency Improvements in Perovskite Solar Cells
}

\section{AUTHOR(S):}

Cho, Yongyoon; Kim, Hyung Do; Zheng, Jianghui; Bing, Jueming; Li, Yong; Zhang, Meng; Green, Martin A.; ... Huang, Shujuan; Ohkita, Hideo; Ho-Baillie, Anita W.Y.

\section{CITATION:}

Cho, Yongyoon ... [et al]. Elucidating Mechanisms behind Ambient Storage-Induced Efficiency Improvements in Perovskite Solar Cells. ACS Energy Letters 2021, 6: 925-933

\section{ISSUE DATE:}

2021-02-15

\section{URL:}

http://hdl.handle.net/2433/262757

\section{RIGHT:}

This document is the Accepted Manuscript version of a Published Work that appeared in final form in Elucidating Mechanisms behind Ambient Storage-Induced Efficiency Improvements in Perovskite Solar Cells, copyright (c) American Chemical Society after peer review and technical editing by the publisher. To access the final edited and published work see https://doi.org/10.1021/acsenergylett.0c02406.; This is not the published version. Please cite only the published version.この論文は出版社版でありません。引用の際には出版社版をご確認ご利用ください。 


\section{Elucidating mechanisms behind ambient storage}

\section{induced efficiency improvements in perovskite}

\section{solar cells}

Yongyoon Cho ${ }^{1,2 \dagger}$, Hyung Do Kim ${ }^{2 \dagger}$, Jianghui Zheng ${ }^{1,3,4}$, Jueming Bing ${ }^{1,3,4}$, Yong Li ${ }^{l}$, Meng

Zhang $^{1}$, Martin A. Green ${ }^{1}$, Atsushi Wakamiya ${ }^{5}$, Shujuan Huang ${ }^{1,6}$, Hideo Ohkita $^{2} *$ and Anita W.Y. Ho-Baillie $e^{1,3,4 *}$

${ }^{1}$ Australian Centre for Advanced Photovoltaics (ACAP),

School of Photovoltaic and Renewable Energy Engineering,

University of New South Wales, Sydney 2052, Australia

${ }^{2}$ Department of Polymer Chemistry, Graduate School of Engineering,

Kyoto University, Katsura, Nishikyo-ku, Kyoto 615-8510, Japan

${ }^{3}$ The University of Sydney Nano Institute, The University of Sydney,

NSW 2006, Australia 
${ }^{4}$ School of physics, University of Sydney,

NSW 2006, Australia

${ }^{5}$ Institute for Chemical Research, Kyoto University,

Uji, Kyoto 611-0011, Japan

${ }^{6}$ School of Engineering, Macquarie University,

Sydney 2109, Australia

${ }^{\dagger}$ These authors contributed equally to this work.

\section{Corresponding Author}

*Anita W.Y. Ho-Baillie. * Hideo Ohkita

*Corresponding authors' e-mail: anita.ho-baillie@ sydney.edu.au, ohkita@ photo.polym.kyotou.ac.jp

\section{ABSTRACT}

Initial improvement in power conversion efficiency (PCE) during ambient storage is often seen in perovskite solar cells (PSCs). In this work, we studied the origin of PCE enhancement by ambient storage on typical n-i-p PSCs. We found improvements in both fill factor and opencircuit voltage during the first two days of storage. By analyzing temperature and light intensity dependent $V_{\mathrm{OC}}$, we found that the charge recombination mechanism changed from surface- to 
bulk-dominated due to defect passivation at the perovskite surface upon storage. In addition, we found that storage improves the conductivity and lowers the highest occupied molecular orbital level of the spiro-OMeTAD improving charge extraction. These results show that there are more than one factor causing the storage-induced-improvements in perovskite solar cells.

\section{TOC GRAPHICS}

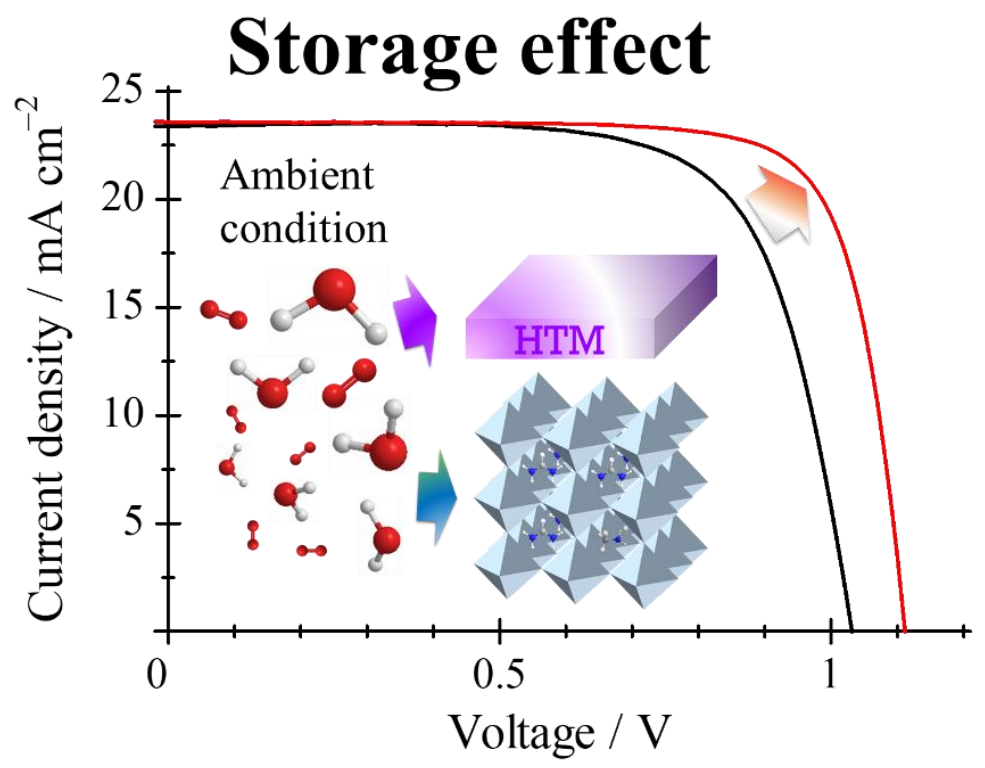


Power conversion efficiency (PCE) of organic-inorganic perovskite solar cells has recently reached $25.5 \%$ independently certified, surpassing that of other emerging solar cells such as dye-sensitized solar cells and organic photovoltaics, and approaching that of record inorganic solar cells. ${ }^{1,2}$ The superior opto-electronic characteristics make it possible to apply perovskites to commercialized Si or other thin film solar cells forming tandem solar cells, and to apply perovskites for lightweight-flexible devices using printable technologies. ${ }^{3-7}$ However, many researches are still struggling to overcome challenges such as the presence of defects, e.g., traps, and instability, e.g., under continuous light illumination, humidity and thermal stimuli. The former can prevent PCE's from reaching the Shockley-Queisser limit. The latter can limit commercialization prospects of perovskite solar devices. ${ }^{7-16}$

To obtain high PCE, a diverse range of engineering techniques including compositional engineering, film formation engineering, defect and surface passivation have been demonstrated to be effective. ${ }^{10,17-25}$ Interestingly, many studies have shown that PCE can be initially improved during the first few days of storage in ambient atmosphere. ${ }^{20,26-32}$ However, the underlying mechanisms for such PCE improvement are not yet fully understood, which will be the focus of this work.

Amongst various layers of perovskite solar cells, electronic properties of hole-transporting material (HTM) such as 2,2',7,7'-tetrakis-(N,N-dip-methoxyphenylamine)-9,9'spirobifluorene) (spiro-OMeTAD), have been reported to change with time. ${ }^{33-36}$ Hawash et al. reported that air exposure resulted in redistribution of a dopant, lithium bis(trifluoromethanesulfonyl)imide (Li-TFSI), in the hole-transporting layer, although fast initial PCE degradation was observed rather than enhancement. ${ }^{35}$ It was also reported that various environmental conditions such as oxygen, nitrogen, and humidity can influence the conductivity of the spiro-OMeTAD layer doped with Li-TFSI. ${ }^{36}$ They found that $\mathrm{H}_{2} \mathrm{O}$ triggered an irreversible increase in electrical conductivity of the doped spiro-OMeTAD layer. Therefore, 
they concluded that the initial PCE increase was due to the conductivity enhancement under ambient condition.

Apart from the changes in HTM properties in ambient storage, temporal changes of perovskite layers have also been studied. Firstly, with respect to the morphology, Roose et al. reported crystallite coalescence of small perovskite grains during the first 4 weeks of storage in the dark and under dry air condition. ${ }^{37}$ As a result, hysteresis in current density-voltage $(J-V)$ characteristics was effectively reduced. Interestingly, this crystallite coalescence was observed to last for as long as 28 days, which is longer than the period (several days) in which the initial PCE increase is generally observed. ${ }^{20,26-28,30,31,38,39}$ Secondly, Bi et al. studied sodium ion diffusion from ITO glass into perovskite grain boundaries under inert and ambient condition. ${ }^{40}$ They found that sodium ion diffusion results in an increase in short-circuit current density $\left(J_{S C}\right)$, which is consistent with the increase in EQE from 400 to $650 \mathrm{~nm}$. On the other hand, only a small increase in open-circuit voltage $\left(V_{\mathrm{OC}}\right)$ was observed, regardless of storage condition. Recently, Fei et al. reported the recrystallization of perovskite grains under inert condition storage (nitrogen-filled glove box). ${ }^{41}$ The PCE drastically increased in the first 2 days and then gradually increased over tens of days. Although the improvement in PCE was attributed to the recrystallization of mixed perovskite that was observed over 58 days, the initial drastic increase in PCE in the first 2 days cannot be explained by the slow recrystallization because no change in the X-ray diffraction (XRD) peak was observed in the first 2 days. Most recently, Moghadamzadeh et al. disputed the crystallite coalescence argument put forward previously as they found no evidence of grain size change or spontaneous coalescence of the perovskite crystallites. ${ }^{42}$ Instead, the authors suggested that the initial PCE improvement was due to the reduction of trap-assisted non-radiative recombination possibly due to strain relaxation confirmed by XRD measurement results. Table S1 summarizes reports of storage effects published to date including storage conditions and time scales. It is clear that there are no 
reports that study the combined effects of storage on cell performance caused by changes in both perovskite and HTM layers which will be the focus of this work.

Herein, we study the origins of initial PCE increase by ambient storage effect on perovskite solar cells with an $n-i-p$ device structure using $\left(\mathrm{FAPbI}_{3}\right)_{0.85}\left(\mathrm{MAPbBr}_{3}\right)_{0.15}$ perovskite as the absorber layer and spiro-OMeTAD as the HTM. In the first 2 days of storage, PCE increased under ambient with a relative humidity $(\mathrm{RH})$ of $20 \pm 10 \%$. For both fresh and stored samples, we measured photovoltaic properties, time-resolved photoluminescence (TRPL), space-chargelimited current (SCLC), and photoelectron yield spectroscopy (PYS) to examine the film properties. As a result, we found, that the effect of ambient storage on initial cell performance improvement is a combined result of temporal changes in both perovskite and HTM. For the first time, these changes are reported which are (perovskite/HTM interface) surface passivation and changes in conductivity and HOMO energy level in the HTM.

Perovskite solar cells with an n-i-p structure (Figure 1a) were studied in this work. Compact titanium dioxide $\left(\mathrm{c}-\mathrm{TiO}_{2}\right)$ and mesoporous $\mathrm{TiO}_{2}\left(\mathrm{~m}-\mathrm{TiO}_{2}\right)$ were deposited on fluorine-doped tin oxide (FTO) glass substrate. A mixed perovskite solution of $\left(\mathrm{FAPbI}_{3}\right)_{0.85}\left(\mathrm{MAPbBr}_{3}\right)_{0.15}$ with excess $\mathrm{PbI}_{2}(5 \mathrm{~mol} \%)$ was then spin-coated using anti-solvent engineering technique, which was followed by HTM and Au deposition (See details in the Supporting Information). First, we measured time evolution of $J-V$ characteristics of perovskite solar cells stored in ambient atmosphere - room temperature and a controlled RH of $20 \pm 10 \%$ in a desiccator. As shown in Figure 1b, the PCE of the champion device was improved, from 17.1 to $20.4 \%$ after 2 days of storage. This is due to an increase in fill factor $(\mathrm{FF})$ and $V_{\mathrm{OC}}$ while $J_{\mathrm{SC}}$ remained the same and the distribution of all parameters remain fairly similar after 2 days of storage (Figures 1c-f). The increase in FF is due to the reduction of series resistance $R_{\mathrm{S}}$ (Figure $\mathrm{S1}$ ) due to the desirable changes in the HTM upon storage as will be discussed below. There is no clear trend in terms 
of the changes in shunt resistances $R_{\mathrm{SH}}$ with average values $>7 \times 10^{3} \Omega \mathrm{cm}^{2}$ which are respectable reflecting the quality of the films, e.g., pin-hole free. Slight drop in cell performance is observed in devices after 3 and 4 days of ambient storage due to degradation induced by prolonged ambient exposure, consistent with our previous work $^{20,43}$. The photovoltaic parameters are summarized in Table S2. From these results, initial PCE enhancement by storage is observed for the mixed-cation mixed-halide perovskite devices and this work attempts to investigate the underlying mechanisms. 
(a)

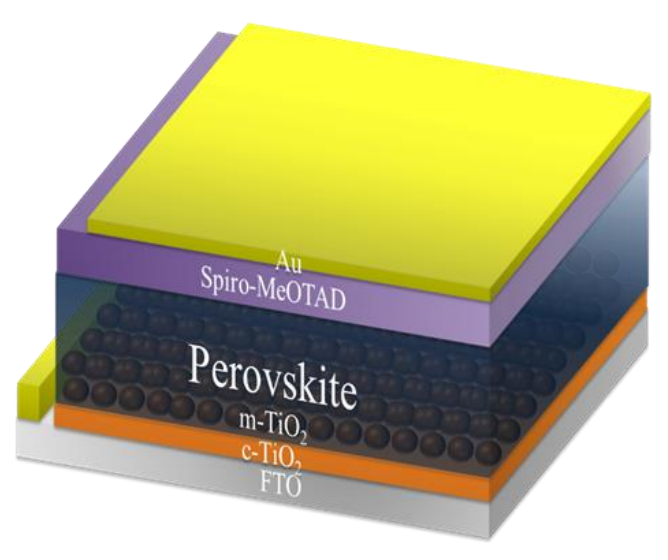

(c)
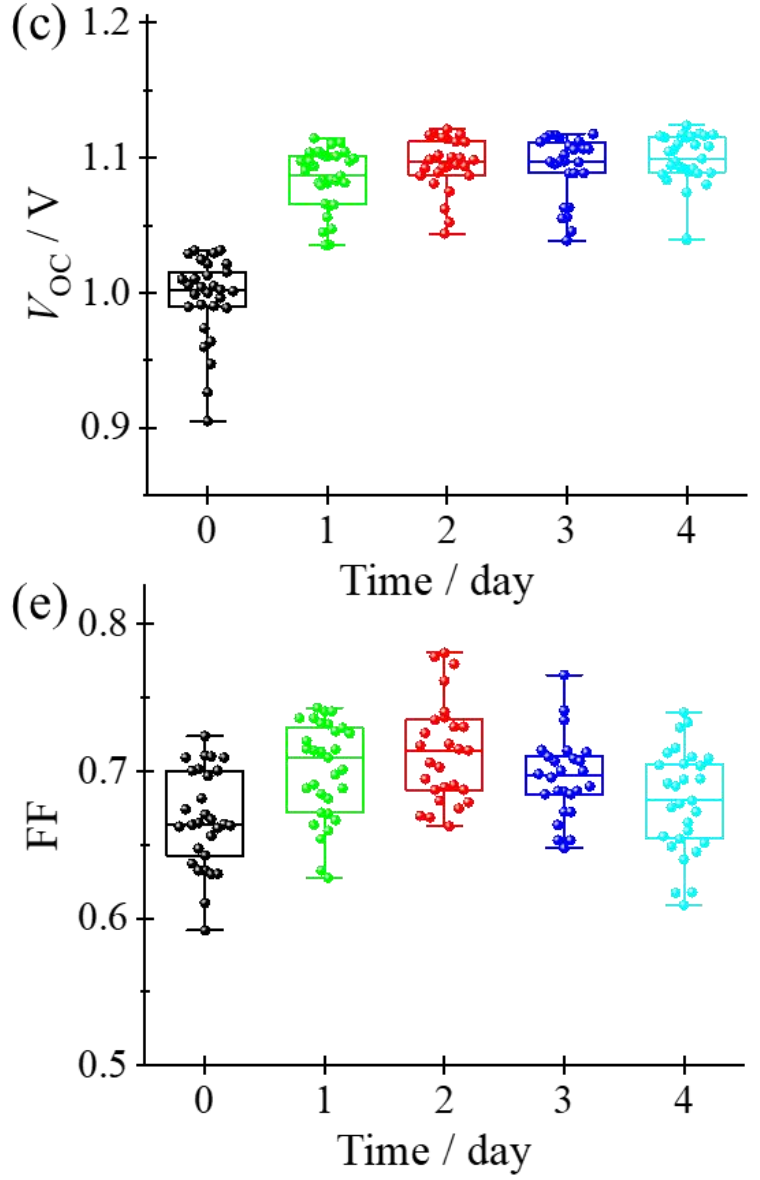

(b)

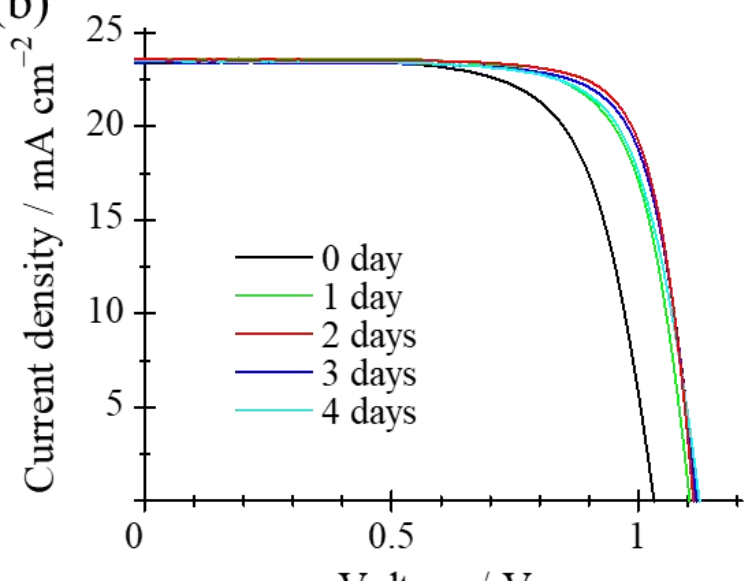

(d)

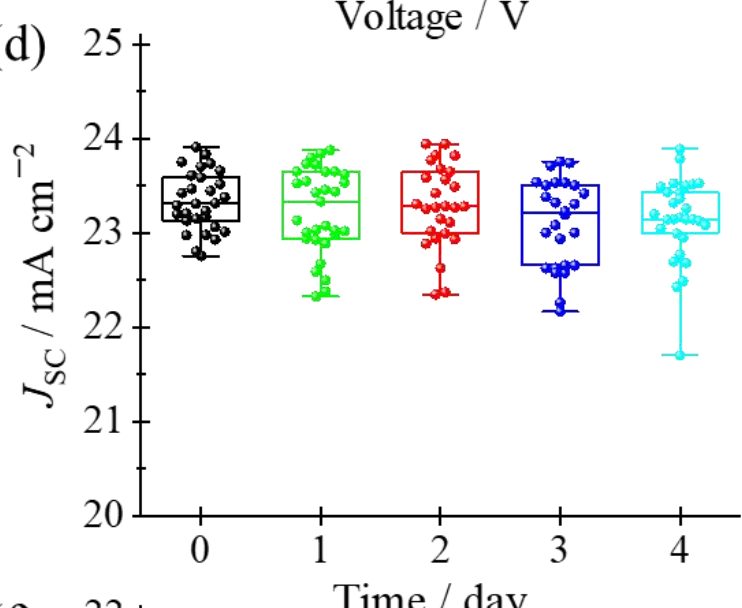

(f)

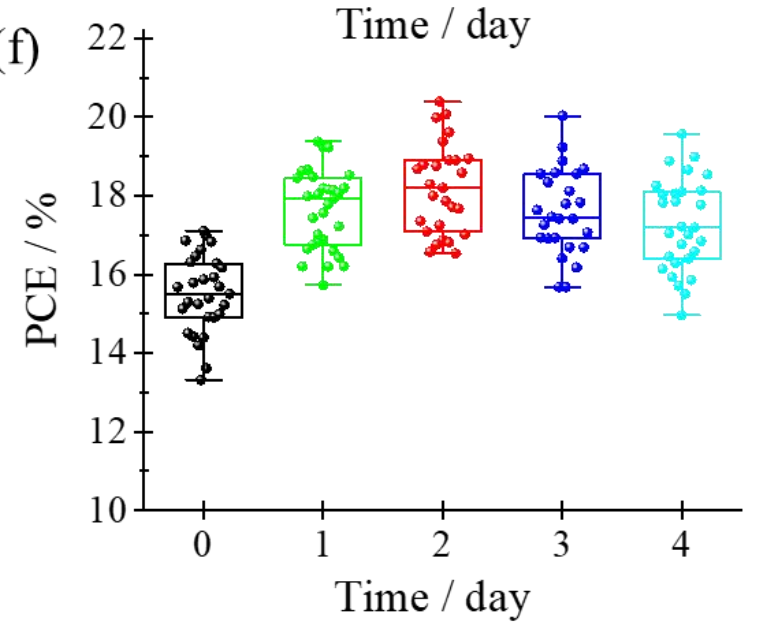

Figure 1. a) Device structure of perovskite solar cells employed in this work. b) Time evolution of the best $J-V$ characteristics of the device stored in the ambient atmosphere. c-f) Scatter plots of photovoltaic parameters measured for 25 devices after various storage times. 
In order to address the origin of the initial increase in $V_{\mathrm{OC}}$, we measured temperature and intensity dependent $V_{\mathrm{OC}}$ for the above perovskite solar cells before and after the ambient storage. ${ }^{4-46}$ for determining dominant recombination mechanisms
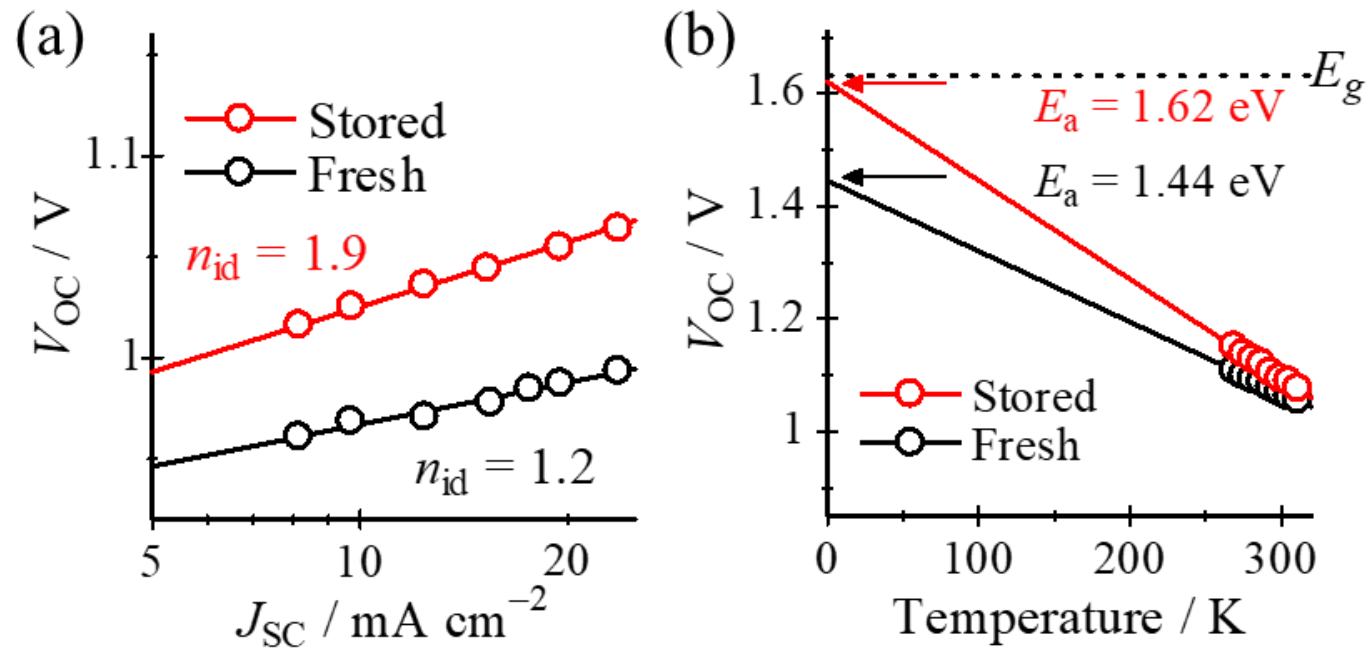

(c) Band edge

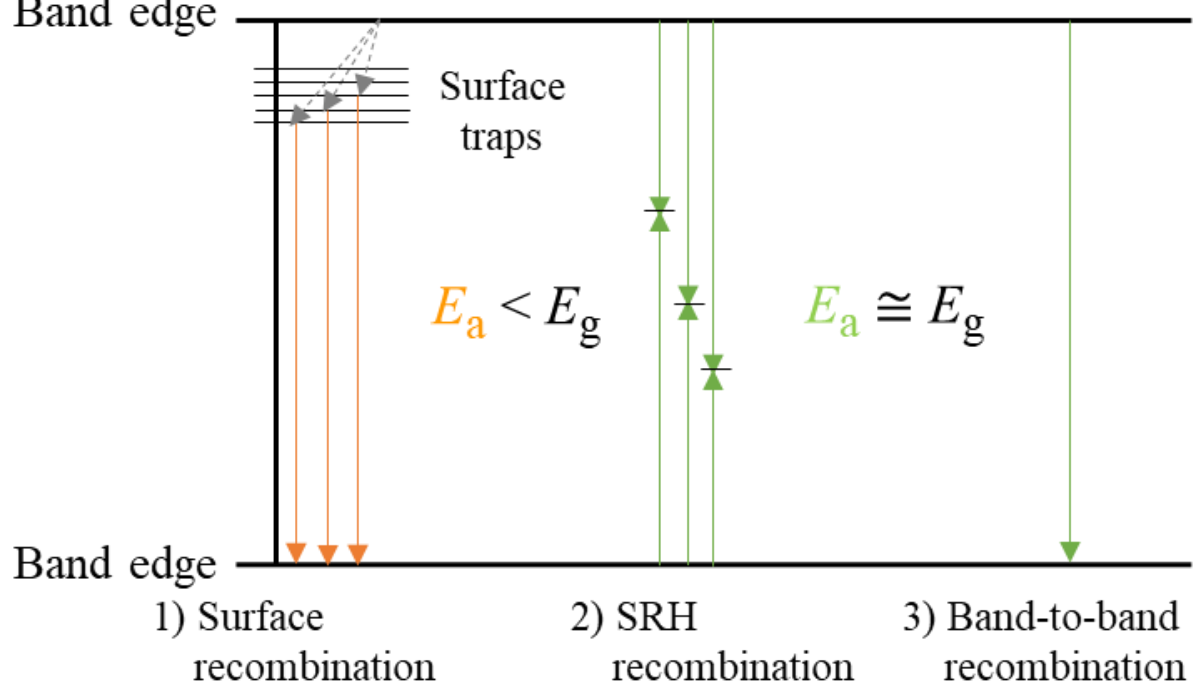

Figure 2. a) Intensity dependent $V_{\mathrm{OC}}$ for a perovskite solar cell before (black curve) and after (red curve) ambient storage. From the slope, $n_{i \mathrm{~d}}$ was evaluated to be 1.2 and 1.8 for the device before and after the ambient storage, respectively. b) Temperature dependent $V_{\mathrm{OC}}$ for a perovskite solar cell before (black curve) and after (red curve) the ambient storage. From the extrapolation of $V_{\mathrm{OC}}$ to $0 \mathrm{~K}, E_{\mathrm{a}}$ was evaluated to be 1.44 and $1.62 \mathrm{eV}$ for the device before and 
after ambient storage, respectively. c) Illustration of energy diagrams for 1) recombination at the surface, 2) SRH recombination, and 3) band-to-band recombination.

Figure 2a shows the intensity dependent $V_{\mathrm{OC}}$ measured for a representative perovskite solar cell before (black curve) and after (red curve) ambient storage for 2 days. Figure $\mathbf{S 3}$ shows the results of the same measurements on multiple perovskite cells to illustrate result reproducibility. Ideality factor $n_{\text {id }}$ calculated (see Supporting Information for details of calculations) from the slopes are on average 1.2 for the fresh device and 1.9 for the aged device. This finding suggests that recombination mechanism changed after storage. For the fresh device, the low $n_{\mathrm{id}}(\sim 1.2)$ is usually desirable for high performance. However, it is not consistent with the low $V_{\mathrm{OC}}$ observed, suggesting that the small $n_{\text {id }}$ is not due to band-to-band direct recombination. Rather, such a small $n_{\text {id }}$ can be explained by the trap-mediated recombination through energetically shallow recombination centers or surface recombination. ${ }^{47,48}$ Similar reports have shown that $n_{\text {id }}$ is near unity with a low $V_{\mathrm{OC}}$ for the device in an inverted structure with PEDOT:PSS as HTM, which is attributed to dominant surface recombination. ${ }^{44,49}$ On the other hand, high $n_{\text {id }}$ near 2 after the storage is consistent with previous reports, indicating that typical ShockleyRead-Hall (SRH) recombination in the perovskite bulk is dominant. ${ }^{44,45,48}$ The increase in $V_{\mathrm{OC}}$ compared to that of fresh devices implies a reduction of trap-mediated or non-radiative recombinations as well.

Figure $2 \mathbf{b}$ shows the temperature dependent $V_{\mathrm{OC}}$ for determining the activation energy $\left(E_{\mathrm{a}}\right)$ of recombination current in the device before and after storage. $E_{\mathrm{a}}$ of the fresh device $(1.44 \mathrm{eV})$ is lower than bandgap energy $E_{\mathrm{g}}$, while an $E_{\mathrm{a}}$ of the aged device $(1.62 \mathrm{eV})$ is close to $E_{\mathrm{g}}$, which is consistent with a previous report. ${ }^{50}$ As reported previously, ${ }^{44,46,51,52}$ the $E_{\mathrm{a}}$ smaller than $E_{\mathrm{g}}$ observed for the fresh device is attributed to sub-bandgap recombination at the surface instead 
of recombination in the perovskite bulk (Figure 2c), which also explains the low $V_{\mathrm{OC}}$ and a $n_{\text {id }}$ value of 1.2. On the other hand, $E_{\mathrm{a}}$ close to $E_{\mathrm{g}}$ was observed for the aged device. This is attributed to bulk recombination such as band-to-band and/or SRH recombination (Figure 2c). ${ }^{44}$ Therefore, we can conclude from these results that recombination mechanisms are different between fresh and aged devices. Trap-mediated surface recombination dominates in fresh devices and bulk recombination dominates in aged devices.

Further evidence was obtained from our analysis of measured external quantum efficiency (EQE) of multiple devices before (black line) and after (red line) aging over a wide wavelength range above and below the $E_{\mathrm{g}}$. We also measured temperature dependent $V_{\mathrm{OC}}$ under various illumination intensities. As shown in Figure 3a, sub-bandgap EQE signals were observed for fresh device but were significantly reduced for aged device (from $10^{-4}$ to $10^{-7}$ above the current detection limit $\left(10^{-8}\right)$. This finding indicates that there are sub-bandgap tail states serving as recombination centers in the fresh device contributing to reduction in $V_{\mathrm{OC}}$. Figures $\mathbf{3 b}$ and $\mathbf{3 c}$ show the temperature dependent $V_{\mathrm{OC}}$ for a representative device before and after storage under different illumination intensities (Enlarged views of the fitting done for Figure $3 \mathrm{~b}$ and $3 \mathrm{c}$ can be found in Figure S4). For the fresh device (Figure 3b), $E_{\mathrm{a}}$ was dependent on illumination intensity: $E_{\mathrm{a}}$ decreases with lower light intensity. This trend indicates increasing contribution of surface recombination related to sub-bandgap tail states rather than bulk recombination because $E_{\mathrm{a}}$ exhibited the intensity dependent $V_{\mathrm{OC}}{ }^{44,51,52}$ For the aged device (Figure 3c), $E_{\mathrm{a}}$ was independent of the illumination intensity, which converged to $E_{\mathrm{g}}$ at $0 \mathrm{~K}$. This is consistent with reduced sub-bandgap state observed in the EQE (Figure 3a). These findings suggest that sub-bandgap tail states at the surface are reduced after storage and hence bulk recombination is dominant in the aged device. 

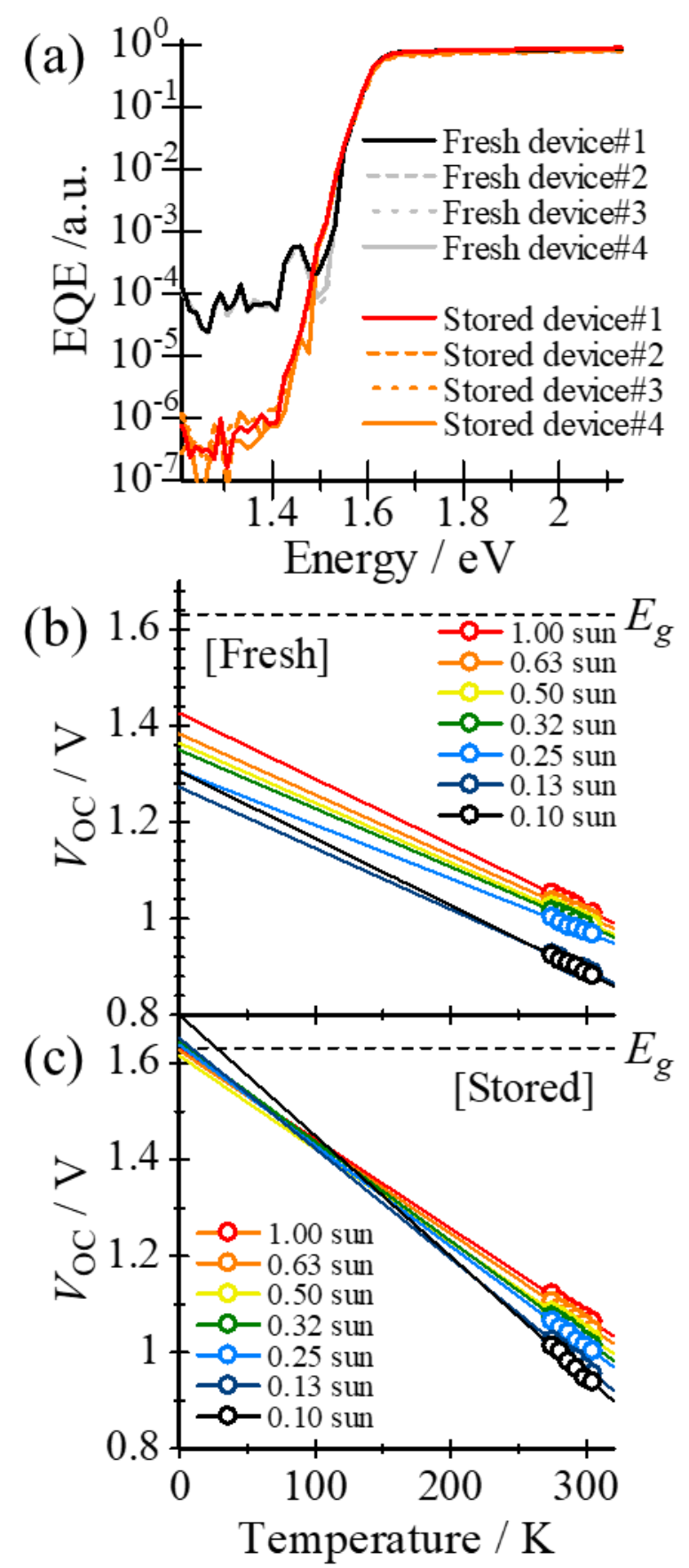

Figure 3. a) EQE of multiple perovskite solar cells before (black line) and after (red line) ambient storage. Temperature dependent $V_{\mathrm{OC}}$ for a representative perovskite solar cell under different illumination intensity b) before and c) after ambient storage. The dotted lines in (b) and (c) represent optical bandgap energy $E_{\mathrm{g}}$. From the extrapolation of $V_{\mathrm{OC}}$ to $0 \mathrm{~K}, E_{\mathrm{a}}$ was evaluated for each illumination intensity. 
While the recombination process has been observed to change from surface dominated to bulk dominated in full devices, it is important to study test devices that allow us to elucidate aging effects on hole transport materials and on perovskite layer separately. As the compact and mesoporous $\mathrm{TiO}_{2}$ layers were formed under ambient atmosphere, aging studies would not reveal any changes. Moghadamzadeh et al., also reported negligible change in the properties of electron transport layer after storage. ${ }^{42}$ Therefore aging effects on perovskite and HTM are only considered in this section.

To investigate the effect of ambient storage on perovskite film only, scanning electron microscopy (SEM) was conducted on films before and after the ambient storage for 2 days (same storage condition for cells in Figures 1 and 2). For direct comparison, SEM images were taken at the same position before and after storage (cf. Figures S5 (a) \& (b)). To rule out effect of electron beam damage during SEM measurement, images were also taken at different positions of the same samples (cf. Figures S5 (c) \& (d)). Grain size distributions for films before and after storage are shown in Figure S6. Results show no change in morphology for films measured at the same or at different positions before and after the storage, consistent with a previous report. ${ }^{42}$ XRD measurement results also show no significant change in crystallinity after ambient storage (Figure S7). We thus exclude perovskite recrystallization or spontaneous crystal coalescence as causes for performance improvement. This is also unlikely due to the longer time scale (> 2 days) for any film recrystallization to take effect especially for the initial PCE increase observed. ${ }^{37}$

To rule out the effect of diffusion of ions such as sodium ${ }^{40}$ from the glass substrate and lithium $^{53,54}$ from the hole transport material, we conducted X-ray photoelectron spectroscopies (XPS) on FTO, FTO/c-TiO 2 , and $\mathrm{FTO} / \mathrm{c}-\mathrm{TiO}_{2} / \mathrm{m}-\mathrm{TiO}_{2}$ test structures (Figure S8) as well as 
perovskite films before and after spiro-OMeTAD "treatment” (see Supporting Information and Figure S9 caption for details). Results show the absence sodium and lithium peaks confirming the absence of ion diffusion during storage.

To further study the storage effect on the perovskite layer and the associated device performance, we fabricated HTM-free perovskite solar cells. Cell performances before and after ambient and $\mathrm{N}_{2}$ storage are shown in Figure 4a and Table S3. Despite poor initial performance due to shunting from the lack of HTM, both $V_{\mathrm{OC}}$ and FF significantly improved after ambient storage, which is consistent with the result of dominant recombination change. On the other hand, no change in PCE was observed after 2 days of inert $\left(\mathrm{N}_{2}\right)$ storage (dash line in Figure 4a and Table S3). As the effect of storage on Au electrode is known to be negligible ${ }^{55}$ we can conclude that ambient storage has a direct positive impact on the perovskite layer alone.

To ascertain if ambient storage has an impact on the energy levels of the perovskite layer, the valence band (VB) levels were evaluated by photoelectron yield spectroscopy (PYS). Results are shown in Figure S10. Negligible change in the VB level was observed before $(5.62 \pm 0.01$ $\mathrm{eV})$ and after $(5.60 \pm 0.01 \mathrm{eV})$ storage. In addition, the optical bandgap (1.63 eV) did not change after storage (Figure S11). We can therefore conclude that ambient storage has negligible impact on energy levels of perovskite layers.

We next evaluate carrier lifetime of a perovskite layer before and after storage via TRPL. Results are shown in Figure 4b. The PL decay curves were fitted with double exponential functions (Figure $\mathbf{4 b}$ ) where the averaged lifetime $\tau_{\text {ave }}$ was calculated using the relationship of $\tau_{\text {ave }}=\sum_{i} \mathrm{~A}_{i} \tau_{i}^{2} / \sum_{i} \mathrm{~A}_{i} \tau_{i \cdot}{ }^{20,56}$ As listed in Table S4, the averaged lifetime of the perovskite film increased from 49.0 to $211 \mathrm{~ns}$ after 2 days of ambient storage, driven by the increase in $\tau_{2}$ in particular, indicating the reduction of non-radiative recombination centers for free carriers (e.g. traps). ${ }^{57,58}$ 
We then evaluate the effect of storage on trap density of perovskite film by analyzing space charge limit current using dark $J-V$ characteristics of perovskite film before and after ambient storage. This is done by determining the trap-filled limit voltage $\left(V_{\mathrm{TFL}}\right)$ which defines the transition from "ohmic" to "trap-filled limit (TFL)" region of the $J-V$ curves (Figure S12). The $V_{\mathrm{TFL}}$ is then used to calculate the trap density. Details are given in the Supporting Information. Results show that ambient storage has a positive impact on the perovskite film reducing trap density from the initial $(1.37 \pm 0.14) \times 10^{16}$ to $(1.03 \pm 0.07) \times 10^{16} \mathrm{~cm}^{-3}$ after storage. These results are consistent with previous reports. ${ }^{58-62}$ In other reports, hydration of the perovskite layer or incorporation of water molecules into perovskite crystal has also been reported to improve film conductivity and to reduce defect level. ${ }^{63,64}$ Surface passivation effects by water molecules has also been reported to enhance photo-generated carrier dynamics in perovskite layers. $^{64}$ Furthermore, humidity-assisted crystallization has also been developed for PCE improvement. ${ }^{65-68}$ While we have ascertained the origins of perovskite improvement from storage: reduced trap density, we will focus on the origins of HTM layer improvement from storage in the next section. 
(a)

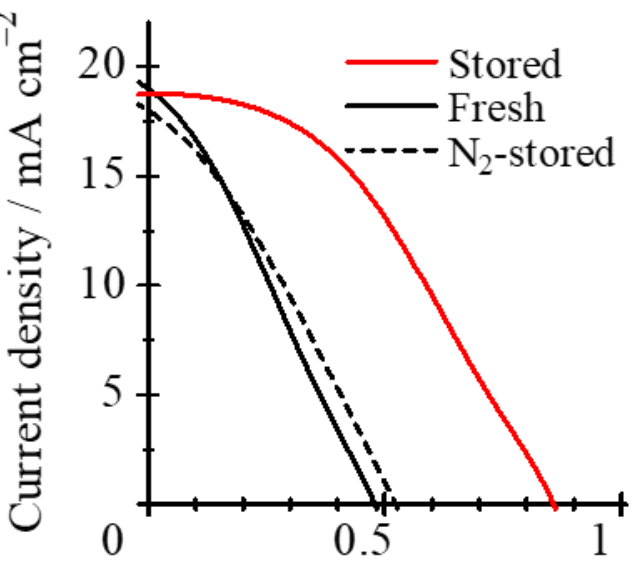

(b)

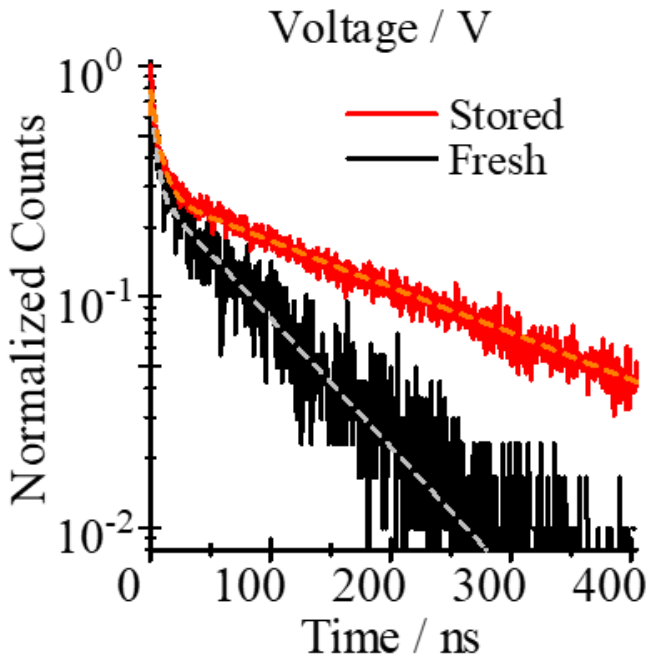

Figure 4. a) Light $J-V$ characteristic of HTM-free perovskite solar cells before (black line) and after ambient (red line) or $\mathrm{N}_{2}$ (dash line) storage. b) PL decay of perovskite films before (black line) and after (red line) ambient storage. The grey and orange lines represent fitted curves using double exponential functions.

Spiro-OMeTAD has been reported to easily oxidize in the initial aging process, ${ }^{33,34,36,69,70}$ especially in the presence of oxygen and Li-TFSI. ${ }^{33,69,70}$ As a result, conductivity of the layer is effectively improved by activated positive ions through these reactions. In addition, dopants can also be re-distributed during oxidation altering the HTM HOMO level and the properties of the perovskite/HTM interface. ${ }^{35,36,71}$ 
To investigate the effect of storage on HTM conductivity, we measured the performance of a perovskite solar cell and the conductivity and the HOMO level of the HTM layer (SpiroOMeTAD) before and after storage. To compare the effect of storage to the effect of doping via FK209 (tris(2-(1H-pyrazol-1-yl)-4-tert-butylpyridine)cobalt(III) tri[bis(trifluoromethane) sulfonimide]) on conductivity, FK209-containing and FK209-free HTM films and cells were fabricated and analyzed for comparisons.

Figure 5a shows the light $J-V$ characteristics of perovskite solar cells using FK209containing and FK-209 free HTM (i.e. spiro-OMeTAD with Li-TFSI and $t$ BP) before and after ambient storage. Results are also summarized in Table S5. As expected, the cell with FK209containing HTM had a slightly higher initial performance (slightly higher FF due to reduced series resistance $R_{\mathrm{S}}$ (Table S5) as the dopant has been reported to assist in the production of spiro-OMeTAD radical cations, resulting in improved conductivity. ${ }^{72-74}$ This is confirmed by conductivity measurement as shown in Figure 5b where initial conductivity of FK209containing film at $t=0$ was higher than that of the fresh FK209-free film. On the other hand, there is a negligible change in $V_{\mathrm{OC}}$ after FK209 incorporation in the HTM for cells either before and after storage (Figure 5a \& Table S5), indicating that surface recombination still dominates in these cells even after the use of FK209 in the HTM. This is also explained by the fact that FK209 dopant does not change the HOMO level of the HTM significantly according to PYS results shown in Figure S13. These results highlight the fact that FK209 incorporation may not be always necessary albeit previous reports on the use of FK209 for improving cells' PCE 71,72,74-76 especially when cells without FK209 in their spiro-OMeTAD (containing Li-TFSI and tBP only) can still achieve high PCE over $22 \% .{ }^{10}$ It may be possible that properties of HTM can be improved by ambient storage alone without FK209 which can be harmful in terms of cells' long-term stability as FK209 can infiltrate the perovskite lattice causing undesirable reaction..$^{53,77}$ 
After ambient storage, both $\mathrm{FF}$ and $V_{\mathrm{OC}}$ were improved for both types of devices regardless of FK209 incorporation (Table S5). The improvement in FF is due to increased conductivity of the HTM (Figure 5b) leading to $R_{\mathrm{S}}$ drop (Table S5). To ascertain the cause for $V_{\mathrm{OC}}$ improvement, we measure the HOMO levels of both types of devices before and after storage of different durations. Results are shown in Figure 5c. The HOMO levels for both types of HTMs (with and without FK209) were around $-5.2 \mathrm{eV}$ initially and dropped to around $-5.5 \mathrm{eV}$ after 2 days of ambient storage. This change is likely to be due to the emergence of divalent cations of spiro-OMeTAD as a result of ambient exposure. ${ }^{36,78}$ The narrowing of the gap between the valence band of the perovskite and the HOMO level of HTM layers as illustrated in Figure 5d (from $0.47 \mathrm{eV}$ to $0.15 \mathrm{eV}$ ) results in better band alignment lowering offset losses and facilitating faster extraction before carriers have the chance of recombining through the sub-bandgap defect states ${ }^{11,79,80}$ at the perovskite / HTM interface (Figure 2c). This is supported by faster PL decay observed for stored perovskite/HTM samples compared to fresh ones as shown in Figure S14. 
(a)

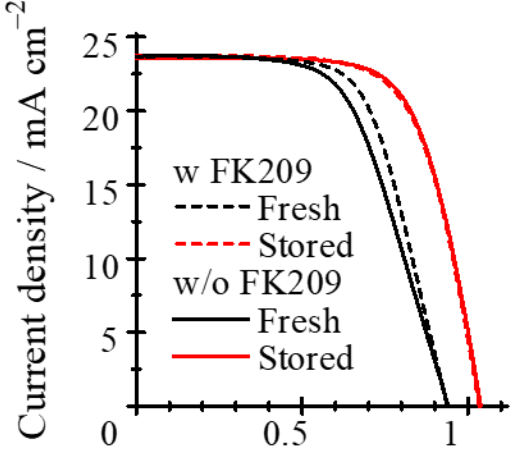

(b)

(c)

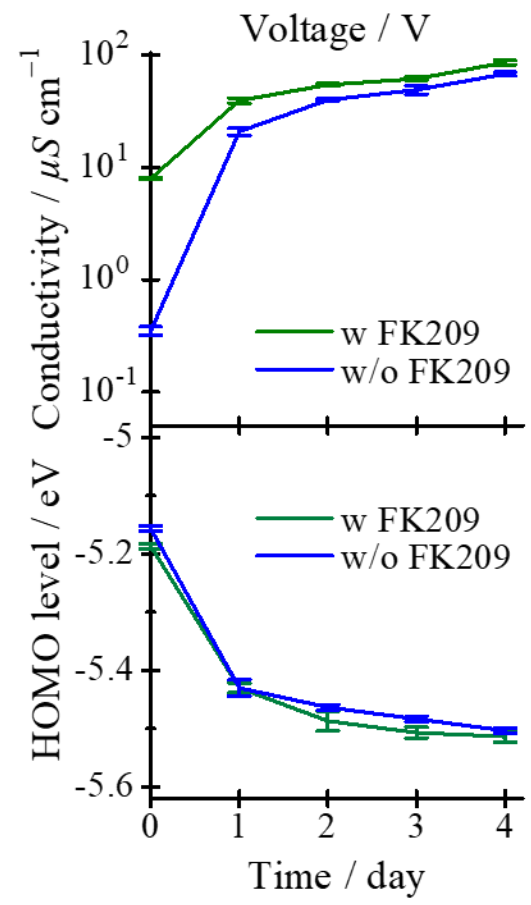

(d)

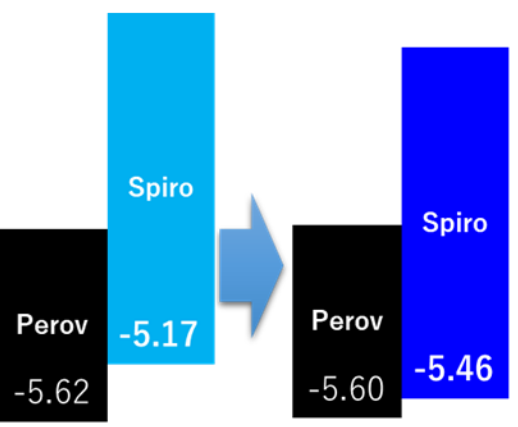

Figure 5. a) Light $J-V$ characteristics of perovskite solar cells with (dash) and without (solid) FK209 in the HTL layer before (black) and after (red) ambient storage. b) Conductivity of FK209-free (blue) and FK209-containing (green) spiro-OMeTAD films as a function of ambient storage time. c) HOMO level of FK209-free (blue) and FK209-containing (green) spiro-OMeTAD as a function of ambient storage time. d) Illustrations of HOMO level change 
of spiro-OMeTAD before (left) and after (right) ambient storage resulting in better band alignment with the perovskite layer.

To prove that the positive impact of storage on cell performance is a combined effect acting on both the perovskite layer and the HTM, we compared a series of full devices that have i) fresh perovskite with fresh HTM (black solid line in Figure S15); ii) 2-day-stored perovskite with 2-day-stored HTM (red solid line in Figure S15); iii) 2-day-stored perovskite with fresh HTM (red line with black markers in Figure S15) and iv) 4-day-stored perovskite with 2-daystored HTM (black line with black markers in Figure S15). Their electrical characteristics are listed in Table S6 in the Supporting Information. Focusing on the 2-day-stored perovskite with the fresh HTM device, its photovoltaic performance is better than the fresh device (cf. red line with black markers and black solid line in Figure S15) showing the effectiveness of ambient storage on improving the perovskite film alone for the PCE improvement. However, its performance is lower than the device where both the perovskite layer and the HTM have been stored for 2 days (cf. red line with black markers and red solid line in Figure S15). Interestingly, additional storage improved PCE even further as can be seen in the device with the 4-day-stored perovskite and 2-day-stored HTM (cf. red line with black markers and black line with black markers in Figure S15).

These findings suggest that ambient storage acts on both the perovskite layer and the HTM. The underlying mechanisms are revealed which conclude i) improved conductivity in the HTM after storage (section 2.3.2) thereby improving FF of associated devices; ii) a reduction in HOMO level in the HTM after storage (section 2.3.2) resulting in better band alignment lowering offset losses and facilitating faster carrier extraction thereby improving $V_{\mathrm{OC}}$ and $\mathrm{FF}$ of associated devices; and iii) improved carrier lifetime and reduced trap density in the perovskite 
layer (section 2.3.1) thereby improving $V_{\mathrm{OC}}$ of associated devices. The last improvement is likely to be due to improved perovskite surface passivation due to reduction of trap-mediated recombination and a change of recombination process from surface dominated to bulk dominated after storage (section 2.2). As part of the supporting information, a preliminary study was conducted to investigate the effects of varying environmental conditions for storage, e.g. inert gas vs oxygen vs humidity (Figure S16 and the corresponding discussions). Negligible change was observed for " $\mathrm{N}_{2}$ " and "Dry air" stored devices but cells that underwent humidity (20 $\pm 10 \%$ RH regardless of gaseous components) storage all experienced initial PCE improvement indicating the underlying improvement mechanisms are linked to hydration process. ${ }^{63-68}$ These results highlight opportunities for future work for more in-depth study into the hydration process for PSCs.

In summary, we studied the effect of storage under controlled ambient atmosphere to understand the mechanisms behind initial PCE improvement of perovskite solar cells that is commonly observed. An average PCE increase from 15.4 to $18.2 \%$ with the maximum PCE of $20.4 \%$ were observed after 2 days of ambient storage. The improvement is only observed where the storage environment contains traces of humidity $(20 \pm 10 \% \mathrm{RH})$. Here, we have distinguished the effects of ambient storage on perovskite film and on the HTM. Ambient storage improves carrier lifetime and reduces trap density in perovskite film alone confirmed by time-resolved photoluminescence and space-charge-limited current analyses, respectively. While for the HTM, for the first time, we found that ambient storage improves its conductivity and reduces its HOMO level facilitating better band alignment with the perovskite confirmed by EQE analysis, four-point probe measurements, and photoelectron yield spectroscopy. This explains the initial improvements of $\mathrm{FF}$ and $V_{\mathrm{OC}}$ for stored devices. By analyzing results of temperature and intensity dependent $V_{\mathrm{OC}}$ measurements, it was found that the dominant 
recombination process changed from surface dominated to bulk dominated upon storage and trap mediated recombinations reduce after storage. Therefore, it is the reduction of surface recombination in stored devices that contributes to the initial improvement of $V_{\mathrm{OC}}$ for stored devices. These findings contribute to the knowledge explaining the widely observed discrepancy in cell performance measured on the same device immediately after fabrication and after a period of storage. These results will inspire future work for improving PCE further by developing interface with less offset losses and highly conductive HTMs deep HOMO levels.

\section{Associated content}

Supporting information

The Supporting Information is available free of charge on the ACS Publications website at DOI: XXXX Experimental details, supplementary characterizations of materials and devices, and tables summarizing previous reports of storage effect, photovoltaic parameters and fitting parameters of TRPL, and figures summarizing results of J-V, SEM, XRD, XPS, PYS, EQE, SCLC, TRPL, and environmental test.

\section{Acknowledgments}

The Australian Centre for Advanced Photovoltaics (ACAP) encompasses the Australianbased activities of the Australia U.S. Institute for Advanced Photovoltaics (AUSIAPV) and is supported by the Australian Government through the Australian Renewable Energy Agency (ARENA). We thank to associate professor Tomokazu Umeyama and other researchers at Kyoto university and UNSW for their technical support. This study is also partly supported by a project commissioned by the New Energy and Industrial Technology Development Organization (NEDO), Japan Science and Technology Agency (JST) Advanced Low Carbon 
Technology Research and Development Program (ALCA) Grant Number JPMJAL1603 and JSPS KAKENHI Grand Number JP20F20031. 


\section{References}

(1) Green, M. A.; Dunlop, E. D.; Levi, D. H.; Hohl-Ebinger, J.; Yoshita, M.; Ho-Baillie, A. W. Y. Solar Cell Efficiency Tables (Version 54). Prog. Photovoltaics Res. Appl. 2019, 27 (7), 565-575.

(2) Best solar cell efficiencies chart. (https://www.nrel.gov/pv/cell-efficiency.html) https://www.nrel.gov/pv/cell-efficiency.html.

(3) Zheng, J.; Lau, C. F. J.; Mehrvarz, H.; Ma, F.-J.; Jiang, Y.; Deng, X.; Soeriyadi, A.; Kim, J.; Zhang, M.; Hu, L.; Cui, X.; Lee, D. S.; Bing, J.; Cho, Y.; Chen, C.; Green, M. A.; Huang, S.; Ho-Baillie, A. W. Y. Large Area Efficient Interface Layer Free Monolithic Perovskite/Homo-Junction-Silicon Tandem Solar Cell with over 20\% Efficiency. Energy Environ. Sci. 2018, 11 (9), 2432-2443.

(4) Zhao, L.; Gao, J.; Lin, Y. L.; Yeh, Y.-W.; Lee, K. M.; Yao, N.; Loo, Y.-L.; Rand, B. P. Electrical Stress Influences the Efficiency of CH 3 NH 3 PbI 3 Perovskite Light Emitting Devices. Adv. Mater. 2017, 29 (24), 1605317.

(5) Di Giacomo, F.; Zardetto, V.; D’Epifanio, A.; Pescetelli, S.; Matteocci, F.; Razza, S.; Di Carlo, A.; Licoccia, S.; Kessels, W. M. M.; Creatore, M.; Brown, T. M. Flexible Perovskite Photovoltaic Modules and Solar Cells Based on Atomic Layer Deposited Compact Layers and UV-Irradiated TiO 2 Scaffolds on Plastic Substrates. Adv. Energy Mater. 2015, 5 (8), 1401808.

(6) Zheng, J.; Mehrvarz, H.; Liao, C.; Bing, J.; Cui, X.; Li, Y.; Gonçales, V. R.; Lau, C. F. J.; Lee, D. S.; Li, Y.; Zhang, M.; Kim, J.; Cho, Y.; Caro, L. G.; Tang, S.; Chen, C.; Huang, S.; Ho-Baillie, A. W. Y. Large-Area 23\%-Efficient Monolithic Perovskite/Homojunction-Silicon Tandem Solar Cell with Enhanced UV Stability Using Down-Shifting Material. ACS Energy Lett. 2019, 4 (11), 2623-2631.

(7) Han, T.-H.; Tan, S.; Xue, J.; Meng, L.; Lee, J.-W.; Yang, Y. Interface and Defect Engineering for Metal Halide Perovskite Optoelectronic Devices. Adv. Mater. 2019, 31 (47), 1803515.

(8) Shockley, W.; Queisser, H. J. Detailed Balance Limit of Efficiency of P-n Junction Solar Cells. J. Appl. Phys. 1961, 32 (3), 510-519.

(9) Ozaki, M.; Shimazaki, A.; Jung, M.; Nakaike, Y.; Maruyama, N.; Yakumaru, S.; Rafieh, A. I.; Sasamori, T.; Tokitoh, N.; Ekanayake, P.; Murata, Y.; Murdey, R.; Wakamiya, A. A Purified, Solvent-Intercalated Precursor Complex for Wide-Process-Window Fabrication of Efficient Perovskite Solar Cells and Modules. Angew. Chemie 2019, 131 (28), 9489-9493.

(10) Jiang, Q.; Zhao, Y.; Zhang, X.; Yang, X.; Chen, Y.; Chu, Z.; Ye, Q.; Li, X.; Yin, Z.; You, J. Surface Passivation of Perovskite Film for Efficient Solar Cells. Nat. Photonics 2019, 13 (7), 460-466.

(11) Song, T.; Kanevce, A.; Sites, J. R. Emitter/Absorber Interface of CdTe Solar Cells. J. Appl. Phys. 2016, 119 (23), 233104. 
(12) Aydin, E.; Bastiani, M.; Wolf, S. Defect and Contact Passivation for Perovskite Solar Cells. Adv. Mater. 2019, 31 (25), 1900428.

(13) Bai, Y.; Xiao, S.; Hu, C.; Zhang, T.; Meng, X.; Lin, H.; Yang, Y.; Yang, S. Dimensional Engineering of a Graded 3D-2D Halide Perovskite Interface Enables Ultrahigh V Oc Enhanced Stability in the p-i-n Photovoltaics. Adv. Energy Mater. 2017, 7 (20), 1701038.

(14) Shin, S. S.; Yeom, E. J.; Yang, W. S.; Hur, S.; Kim, M. G.; Im, J.; Seo, J.; Noh, J. H.; Seok, S. Il. Colloidally Prepared La-Doped BaSnO 3 Electrodes for Efficient, Photostable Perovskite Solar Cells. Science (80-. ). 2017, 356 (6334), 167-171.

(15) Chirilă, A.; Reinhard, P.; Pianezzi, F.; Bloesch, P.; Uhl, A. R.; Fella, C.; Kranz, L.; Keller, D.; Gretener, C.; Hagendorfer, H.; Jaeger, D.; Erni, R.; Nishiwaki, S.; Buecheler, S.; Tiwari, A. N. Potassium-Induced Surface Modification of $\mathrm{Cu}(\mathrm{In}, \mathrm{Ga}) \mathrm{Se} 2$ Thin Films for High-Efficiency Solar Cells. Nat. Mater. 2013, 12 (12), 1107-1111.

(16) Cho, Y.; Ohkita, H.; Li, Y.; Bing, J.; Zheng, J.; Huang, S.; Ho-baillie, A. The Effect of 4-Tert-Butylpyridine Removal on Efficiency and Thermal Stability in Perovskite Solar Cells. J. Photopolym. Sci. Technol. 2019, 32 (5), 715-720.

(17) Jeon, N. J.; Noh, J. H.; Yang, W. S.; Kim, Y. C.; Ryu, S.; Seo, J.; Seok, S. Il. Compositional Engineering of Perovskite Materials for High-Performance Solar Cells. Nature 2015, 517 (7535), 476-480.

(18) Jeon, N. J.; Noh, J. H.; Kim, Y. C.; Yang, W. S.; Ryu, S.; Seok, S. Il. Solvent Engineering for High-Performance Inorganic-Organic Hybrid Perovskite Solar Cells. Nat. Mater. 2014, 13 (9), 897-903.

(19) Bing, J.; Kim, J.; Zhang, M.; Zheng, J.; Lee, D. S.; Cho, Y.; Deng, X.; Lau, C. F. J.; Li, Y.; Green, M. A.; Huang, S.; Ho-Baillie, A. W. Y. The Impact of a Dynamic Two-Step Solution Process on Film Formation of Cs 0.15 (MA 0.7 FA 0.3 ) 0.85 PbI 3 Perovskite and Solar Cell Performance. Small 2019, 15 (9), 1804858.

(20) Cho, Y.; Soufiani, A. M.; Yun, J. S.; Kim, J.; Lee, D. S.; Seidel, J.; Deng, X.; Green, M. A.; Huang, S.; Ho-Baillie, A. W. Y. Mixed 3D-2D Passivation Treatment for MixedCation Lead Mixed-Halide Perovskite Solar Cells for Higher Efficiency and Better Stability. Adv. Energy Mater. 2018, 8 (20), 1703392.

(21) Jung, E. H.; Jeon, N. J.; Park, E. Y.; Moon, C. S.; Shin, T. J.; Yang, T.-Y.; Noh, J. H.; Seo, J. Efficient, Stable and Scalable Perovskite Solar Cells Using Poly(3Hexylthiophene). Nature 2019, 567 (7749), 511-515.

(22) Li, Y.; Shi, J.; Zheng, J.; Bing, J.; Yuan, J.; Cho, Y.; Tang, S.; Zhang, M.; Yao, Y.; Lau, C. F. J.; Lee, D. S.; Liao, C.; Green, M. A.; Huang, S.; Ma, W.; Ho-Baillie, A. W. Y. Acetic Acid Assisted Crystallization Strategy for High Efficiency and Long - Term Stable Perovskite Solar Cell. Adv. Sci. 2020, 7 (5), 1903368.

(23) Bing, J.; Lee, D. S.; Zheng, J.; Zhang, M.; Li, Y.; Kim, J.; Lau, C. F. J.; Cho, Y.; Green, M. A.; Huang, S.; Ho-Baillie, A. W. Y. Deconstruction-Assisted Perovskite Formation for Sequential Solution Processing of Cs0.15(MA0.7FA0.3)0.85PbI3 Solar Cells. Sol. Energy Mater. Sol. Cells 2019, 203 (July), 110200.

(24) Zhang, M.; Bing, J.; Cho, Y.; Li, Y.; Zheng, J.; Lau, C. F. J.; Green, M. A.; Huang, S.; 
Ho-Baillie, A. W. Y. Synergistic Effect of Potassium and Iodine from Potassium Triiodide Complex Additive on Gas-Quenched Perovskite Solar Cells. Nano Energy 2019, 63 (June), 103853.

(25) Kim, H. Do; Ohkita, H.; Benten, H.; Ito, S. Photovoltaic Performance of Perovskite Solar Cells with Different Grain Sizes. Adv. Mater. 2016, 28 (5), 917-922.

(26) Deng, Y.; Dong, Q.; Bi, C.; Yuan, Y.; Huang, J. Air-Stable, Efficient Mixed-Cation Perovskite Solar Cells with $\mathrm{Cu}$ Electrode by Scalable Fabrication of Active Layer. $A d v$. Energy Mater. 2016, 6 (11), 1600372.

(27) Lee, D. S.; Yun, J. S.; Kim, J.; Soufiani, A. M.; Chen, S.; Cho, Y.; Deng, X.; Seidel, J.; Lim, S.; Huang, S.; Ho-Baillie, A. W. Y. Passivation of Grain Boundaries by Phenethylammonium in Formamidinium-Methylammonium Lead Halide Perovskite Solar Cells. ACS Energy Lett. 2018, 3 (3), 647-654.

(28) You, J.; Meng, L.; Song, T.-B.; Guo, T.-F.; Yang, Y. (Michael); Chang, W.-H.; Hong, Z.; Chen, H.; Zhou, H.; Chen, Q.; Liu, Y.; De Marco, N.; Yang, Y. Improved Air Stability of Perovskite Solar Cells via Solution-Processed Metal Oxide Transport Layers. Nat. Nanotechnol. 2016, 11 (1), 75-81.

(29) Paek, S.; Schouwink, P.; Athanasopoulou, E. N.; Cho, K. T.; Grancini, G.; Lee, Y.; Zhang, Y.; Stellacci, F.; Nazeeruddin, M. K.; Gao, P. From Nano- to Micrometer Scale: The Role of Antisolvent Treatment on High Performance Perovskite Solar Cells. Chem. Mater. 2017, 29 (8), 3490-3498.

(30) Li, N.; Zhu, Z.; Chueh, C.-C.; Liu, H.; Peng, B.; Petrone, A.; Li, X.; Wang, L.; Jen, A. K. Y. Mixed Cation FA x PEA 1- x PbI 3 with Enhanced Phase and Ambient Stability toward High-Performance Perovskite Solar Cells. Adv. Energy Mater. 2017, 7 (1), 1601307.

(31) Zhou, Y.; Wang, F.; Cao, Y.; Wang, J.-P.; Fang, H.-H.; Loi, M. A.; Zhao, N.; Wong, C.P. Benzylamine-Treated Wide-Bandgap Perovskite with High Thermal-Photostability and Photovoltaic Performance. Adv. Energy Mater. 2017, 7 (22), 1701048.

(32) Ozaki, M.; Ishikura, Y.; Truong, M. A.; Liu, J.; Okada, I.; Tanabe, T.; Sekimoto, S.; Ohtsuki, T.; Murata, Y.; Murdey, R.; Wakamiya, A. Iodine-Rich Mixed Composition Perovskites Optimised for Tin $(<\mathrm{scp}>\mathrm{iv}</ \mathrm{Scp}>$ ) Oxide Transport Layers: The Influence of Halide Ion Ratio, Annealing Time, and Ambient Air Aging on Solar Cell Performance. J. Mater. Chem. A 2019, 7 (28), 16947-16953.

(33) Wang, S.; Yuan, W.; Meng, Y. S. Spectrum-Dependent Spiro-OMeTAD Oxidization Mechanism in Perovskite Solar Cells. ACS Appl. Mater. Interfaces 2015, 7 (44), 2479124798.

(34) Hawash, Z.; Ono, L. K.; Qi, Y. Recent Advances in Spiro-MeOTAD Hole Transport Material and Its Applications in Organic-Inorganic Halide Perovskite Solar Cells. Adv. Mater. Interfaces 2018, 5 (1), 1700623.

(35) Hawash, Z.; Ono, L. K.; Raga, S. R.; Lee, M. V.; Qi, Y. Air-Exposure Induced Dopant Redistribution and Energy Level Shifts in Spin-Coated Spiro-MeOTAD Films. Chem. Mater. 2015, 27 (2), 562-569. 
(36) Hawash, Z.; Ono, L. K.; Qi, Y. Moisture and Oxygen Enhance Conductivity of LiTFSIDoped Spiro-MeOTAD Hole Transport Layer in Perovskite Solar Cells. Adv. Mater. Interfaces 2016, 3 (13), 1600117.

(37) Roose, B.; Ummadisingu, A.; Correa-Baena, J.-P.; Saliba, M.; Hagfeldt, A.; Graetzel, M.; Steiner, U.; Abate, A. Spontaneous Crystal Coalescence Enables Highly Efficient Perovskite Solar Cells. Nano Energy 2017, 39 (June), 24-29.

(38) De Bastiani, M.; Aydin, E.; Allen, T.; Walter, D.; Fell, A.; Peng, J.; Gasparini, N.; Troughton, J.; Baran, D.; Weber, K.; White, T. P.; De Wolf, S. Interfacial Dynamics and Contact Passivation in Perovskite Solar Cells. Adv. Electron. Mater. 2019, 5 (1), 1800500.

(39) Cho, K. T.; Paek, S.; Grancini, G.; Roldán-Carmona, C.; Gao, P.; Lee, Y.; Nazeeruddin, M. K. Highly Efficient Perovskite Solar Cells with a Compositionally Engineered Perovskite/Hole Transporting Material Interface. Energy Environ. Sci. 2017, 10 (2), 621-627.

(40) Bi, C.; Zheng, X.; Chen, B.; Wei, H.; Huang, J. Spontaneous Passivation of Hybrid Perovskite by Sodium Ions from Glass Substrates: Mysterious Enhancement of Device Efficiency Revealed. ACS Energy Lett. 2017, 2 (6), 1400-1406.

(41) Fei, C.; Wang, H. Age-Induced Recrystallization in Perovskite Solar Cells. Org. Electron. 2019, 68 (January), 143-150.

(42) Moghadamzadeh, S.; Hossain, I. M.; Jakoby, M.; Abdollahi Nejand, B.; Rueda-Delgado, D.; Schwenzer, J. A.; Gharibzadeh, S.; Abzieher, T.; Khan, M. R.; Haghighirad, A. A.; Howard, I. A.; Richards, B. S.; Lemmer, U.; Paetzold, U. W. Spontaneous Enhancement of the Stable Power Conversion Efficiency in Perovskite Solar Cells. J. Mater. Chem. A 2020, 8 (2), 670-682.

(43) Wang, Q.; Chen, B.; Liu, Y.; Deng, Y.; Bai, Y.; Dong, Q.; Huang, J. Scaling Behavior of Moisture-Induced Grain Degradation in Polycrystalline Hybrid Perovskite Thin Films. Energy Environ. Sci. 2017, 10 (2), 516-522.

(44) Tress, W.; Yavari, M.; Domanski, K.; Yadav, P.; Niesen, B.; Correa Baena, J. P.; Hagfeldt, A.; Graetzel, M. Interpretation and Evolution of Open-Circuit Voltage, Recombination, Ideality Factor and Subgap Defect States during Reversible LightSoaking and Irreversible Degradation of Perovskite Solar Cells. Energy Environ. Sci. 2018, 11 (1), 151-165.

(45) Kim, H. Do; Yanagawa, N.; Shimazaki, A.; Endo, M.; Wakamiya, A.; Ohkita, H.; Benten, H.; Ito, S. Origin of Open-Circuit Voltage Loss in Polymer Solar Cells and Perovskite Solar Cells. ACS Appl. Mater. Interfaces 2017, 9 (23), 19988-19997.

(46) Kim, H. Do; Miyamoto, Y.; Kubota, H.; Yamanari, T.; Ohkita, H. Open-Circuit Voltage Loss in CH 3 NH 3 SnI 3 Perovskite Solar Cells. Chem. Lett. 2017, 46 (2), 253-256.

(47) Calado, P.; Burkitt, D.; Yao, J.; Troughton, J.; Watson, T. M.; Carnie, M. J.; Telford, A. M.; O’Regan, B. C.; Nelson, J.; Barnes, P. R. F. Identifying Dominant Recombination Mechanisms in Perovskite Solar Cells by Measuring the Transient Ideality Factor. Phys. Rev. Appl. 2019, 11 (4), 1. 
(48) Caprioglio, P.; Wolff, C. M.; Sandberg, O. J.; Armin, A.; Rech, B.; Albrecht, S.; Neher, D.; Stolterfoht, M. On the Origin of the Ideality Factor in Perovskite Solar Cells. Adv. Energy Mater. 2020, 10 (27), 2000502.

(49) Tress, W. Perovskite Solar Cells on the Way to Their Radiative Efficiency Limit Insights Into a Success Story of High Open-Circuit Voltage and Low Recombination. Adv. Energy Mater. 2017, 7 (14), 1602358.

(50) Green, M. A.; Ho-Baillie, A. W. Y. Pushing to the Limit: Radiative Efficiencies of Recent Mainstream and Emerging Solar Cells. ACS Energy Lett. 2019, 4 (7), 1639-1644.

(51) Grover, S.; Li, J. V. Theory and Analysis of Temperature Coefficient of Open-Circuit Voltage (DVOC/DT) in Heterojunction Solar Cells. In 2015 IEEE 42nd Photovoltaic Specialist Conference (PVSC); IEEE, 2015; pp 1-3.

(52) Thompson, C. P.; Hegedus, S.; Shafarman, W.; Desai, D. Temperature Dependence of VOC in CdTe and $\mathrm{Cu}(\mathrm{InGa})(\mathrm{SeS}) 2$-Based Solar Cells. In 2008 33rd IEEE Photovolatic Specialists Conference; IEEE, 2008; pp 1-6.

(53) Li, Z.; Xiao, C.; Yang, Y.; Harvey, S. P.; Kim, D. H.; Christians, J. A.; Yang, M.; Schulz, P.; Nanayakkara, S. U.; Jiang, C.-S.; Luther, J. M.; Berry, J. J.; Beard, M. C.; Al-Jassim, M. M.; Zhu, K. Extrinsic Ion Migration in Perovskite Solar Cells. Energy Environ. Sci. 2017, 10 (5), 1234-1242.

(54) Xiao, C.; Zhang, F.; Li, Z.; Harvey, S. P.; Chen, X.; Wang, K.; Jiang, C.-S.; Zhu, K.; AlJassim, M. Inhomogeneous Doping of Perovskite Materials by Dopants from HoleTransport Layer. Matter 2020, 2 (1), 261-272.

(55) Lee, D. G.; Kim, M.; Wang, S.; Kim, B. J.; Meng, Y. S.; Jung, H. S. Effect of Metal Electrodes on Aging-Induced Performance Recovery in Perovskite Solar Cells. ACS Appl. Mater. Interfaces 2019, 11 (51), 48497-48504.

(56) Kim, J.; Yun, J. S.; Cho, Y.; Lee, D. S.; Wilkinson, B.; Soufiani, A. M.; Deng, X.; Zheng, J.; Shi, A.; Lim, S.; Chen, S.; Hameiri, Z.; Zhang, M.; Lau, C. F. J.; Huang, S.; Green, M. A.; Ho-Baillie, A. W. Y. Overcoming the Challenges of Large-Area High-Efficiency Perovskite Solar Cells. ACS Energy Lett. 2017, 2 (9), 1978-1984.

(57) Yamada, Y.; Yamada, T.; Shimazaki, A.; Wakamiya, A.; Kanemitsu, Y. Interfacial Charge-Carrier Trapping in CH3NH3PbI3-Based Heterolayered Structures Revealed by Time-Resolved Photoluminescence Spectroscopy. J. Phys. Chem. Lett. 2016, 7 (11), 1972-1977.

(58) Kim, H. Do; Ohkita, H. Charge Traps in Lead-Halide Perovskites with Different Grain Sizes. Jpn. J. Appl. Phys. 2018, 57 (8S3), 08RE03.

(59) Son, D.-Y.; Kim, S.-G.; Seo, J.-Y.; Lee, S.-H.; Shin, H.; Lee, D.; Park, N.-G. Universal Approach toward Hysteresis-Free Perovskite Solar Cell via Defect Engineering. J. Am. Chem. Soc. 2018, 140 (4), 1358-1364.

(60) Guo, Y.; Ma, J.; Lei, H.; Yao, F.; Li, B.; Xiong, L.; Fang, G. Enhanced Performance of Perovskite Solar Cells via Anti-Solvent Nonfullerene Lewis Base IT-4F Induced TrapPassivation. J. Mater. Chem. A 2018, 6 (14), 5919-5925. 
(61) Liu, Z.; Qiu, L.; Juarez-Perez, E. J.; Hawash, Z.; Kim, T.; Jiang, Y.; Wu, Z.; Raga, S. R.; Ono, L. K.; Liu, S.; Qi, Y. Gas-Solid Reaction Based over One-Micrometer Thick Stable Perovskite Films for Efficient Solar Cells and Modules. Nat. Commun. 2018, 9 (1), 3880.

(62) Zhang, Y.; Kim, S.-G.; Lee, D.; Shin, H.; Park, N.-G. Bifacial Stamping for High Efficiency Perovskite Solar Cells. Energy Environ. Sci. 2019, 12 (1), 308-321.

(63) García-Fernández, A.; Moradi, Z.; Bermúdez-García, J. M.; Sánchez-Andújar, M.; Gimeno, V. A.; Castro-García, S.; Señarís-Rodríguez, M. A.; Mas-Marzá, E.; GarciaBelmonte, G.; Fabregat-Santiago, F. Effect of Environmental Humidity on the Electrical Properties of Lead Halide Perovskites. J. Phys. Chem. C 2019, 123 (4), 2011-2018.

(64) Song, Z.; Shrestha, N.; Watthage, S. C.; Liyanage, G. K.; Almutawah, Z. S.; Ahangharnejhad, R. H.; Phillips, A. B.; Ellingson, R. J.; Heben, M. J. Impact of Moisture on Photoexcited Charge Carrier Dynamics in Methylammonium Lead Halide Perovskites. J. Phys. Chem. Lett. 2018, 9 (21), 6312-6320.

(65) Eperon, G. E.; Habisreutinger, S. N.; Leijtens, T.; Bruijnaers, B. J.; van Franeker, J. J.; DeQuilettes, D. W.; Pathak, S.; Sutton, R. J.; Grancini, G.; Ginger, D. S.; Janssen, R. A. J.; Petrozza, A.; Snaith, H. J. The Importance of Moisture in Hybrid Lead Halide Perovskite Thin Film Fabrication. ACS Nano 2015, 9 (9), 9380-9393.

(66) You, J.; Yang, Y. (Michael); Hong, Z.; Song, T.-B.; Meng, L.; Liu, Y.; Jiang, C.; Zhou, H.; Chang, W.-H.; Li, G.; Yang, Y. Moisture Assisted Perovskite Film Growth for High Performance Solar Cells. Appl. Phys. Lett. 2014, 105 (18), 183902.

(67) Wu, C.-G.; Chiang, C.-H.; Tseng, Z.-L.; Nazeeruddin, M. K.; Hagfeldt, A.; Grätzel, M. High Efficiency Stable Inverted Perovskite Solar Cells without Current Hysteresis. Energy Environ. Sci. 2015, 8 (9), 2725-2733.

(68) Cronin, H. M.; Jayawardena, K. D. G. I.; Stoeva, Z.; Shkunov, M.; Silva, S. R. P. Effects of Ambient Humidity on the Optimum Annealing Time of Mixed-Halide Perovskite Solar Cells. Nanotechnology 2017, 28 (11), 114004.

(69) Schloemer, T. H.; Christians, J. A.; Luther, J. M.; Sellinger, A. Doping Strategies for Small Molecule Organic Hole-Transport Materials: Impacts on Perovskite Solar Cell Performance and Stability. Chem. Sci. 2019, 10 (7), 1904-1935.

(70) Abate, A.; Leijtens, T.; Pathak, S.; Teuscher, J.; Avolio, R.; Errico, M. E.; Kirkpatrik, J.; Ball, J. M.; Docampo, P.; McPherson, I.; Snaith, H. J. Lithium Salts as "Redox Active" p-Type Dopants for Organic Semiconductors and Their Impact in Solid-State DyeSensitized Solar Cells. Phys. Chem. Chem. Phys. 2013, 15 (7), 2572.

(71) Wang, X.; Wu, J.; Yang, Y.; Liu, X.; Guo, Q.; Song, Z.; Li, G.; Lan, Z.; Huang, M. High Performance and Stable Perovskite Solar Cells Using Vanadic Oxide as a Dopant for Spiro-OMeTAD. J. Mater. Chem. A 2019, 7 (21), 13256-13264.

(72) Noh, J. H.; Jeon, N. J.; Choi, Y. C.; Nazeeruddin, M. K.; Grätzel, M.; Seok, S. Il. Nanostructured TiO2/CH3NH3PbI3 Heterojunction Solar Cells Employing SpiroOMeTAD/Co-Complex as Hole-Transporting Material. J. Mater. Chem. A 2013, 1 (38), 11842.

(73) Li, Z.; Tinkham, J.; Schulz, P.; Yang, M.; Kim, D. H.; Berry, J.; Sellinger, A.; Zhu, K. 
Acid Additives Enhancing the Conductivity of Spiro-OMeTAD Toward High-Efficiency and Hysteresis-Less Planar Perovskite Solar Cells. Adv. Energy Mater. 2017, 7 (4), 1601451.

(74) Ye, T.; Wang, J.; Chen, W.; Yang, Y.; He, D. Improved Performance and Reproducibility of Perovskite Solar Cells by Well-Soluble Tris(Pentafluorophenyl)Borane as a p-Type Dopant. ACS Appl. Mater. Interfaces 2017, 9 (21), 17923-17931.

(75) Seo, J.-Y.; Kim, H.-S.; Akin, S.; Stojanovic, M.; Simon, E.; Fleischer, M.; Hagfeldt, A.; Zakeeruddin, S. M.; Grätzel, M. Novel P-Dopant toward Highly Efficient and Stable Perovskite Solar Cells. Energy Environ. Sci. 2018, 11 (10), 2985-2992.

(76) Saygili, Y.; Turren-Cruz, S.-H.; Olthof, S.; Saes, B. W. H.; Pehlivan, I. B.; Saliba, M.; Meerholz, K.; Edvinsson, T.; Zakeeruddin, S. M.; Grätzel, M.; Correa-Baena, J.-P.; Hagfeldt, A.; Freitag, M.; Tress, W. Planar Perovskite Solar Cells with High OpenCircuit Voltage Containing a Supramolecular Iron Complex as Hole Transport Material Dopant. ChemPhysChem 2018, 19 (11), 1363-1370.

(77) Wong-Stringer, M.; Bishop, J. E.; Smith, J. A.; Mohamad, D. K.; Parnell, A. J.; Kumar, V.; Rodenburg, C.; Lidzey, D. G. Efficient Perovskite Photovoltaic Devices Using Chemically Doped PCDTBT as a Hole-Transport Material. J. Mater. Chem. A 2017, 5 (30), 15714-15723.

(78) Nguyen, W. H.; Bailie, C. D.; Unger, E. L.; McGehee, M. D. Enhancing the HoleConductivity of Spiro-OMeTAD without Oxygen or Lithium Salts by Using Spiro(TFSI) 2 in Perovskite and Dye-Sensitized Solar Cells. J. Am. Chem. Soc. 2014, 136 (31), 10996-11001.

(79) Crovetto, A.; Hansen, O. What Is the Band Alignment of $\mathrm{Cu} 2 \mathrm{ZnSn}(\mathrm{S}, \mathrm{Se}) 4$ Solar Cells? Sol. Energy Mater. Sol. Cells 2017, 169 (May), 177-194.

(80) Shi, J.; Xu, X.; Li, D.; Meng, Q. Interfaces in Perovskite Solar Cells. Small 2015, 11 (21), 2472-2486. 
